\title{
Real-Time Reverse Transcription PCR
}

\author{
Stephen A. Bustin \\ University of London, London, U.K.
}

\section{INTRODUCTION}

Real-time, fluorescence-based reverse transcription polymerase chain reaction (RT-PCR $)^{[1]}$ has been transformed from an experimental technology into a mainstream scientific tool for the detection of RNA. ${ }^{[2]}$ This is because of several factors: 1) it is a homogeneous assay, which eliminates the requirement for post-PCR processing; 2) it has a wide dynamic range; 3) there is little interassay variation; and 4) it realizes the inherent quantitative capacity ${ }^{[3]}$ of PCR-based assays, making it a quantitative, rather than a qualitative, assay. These properties match the evident requirement in molecular medicine for quantitative data (e.g., for measuring viral load, ${ }^{[4]}$ monitoring of occult disease in cancer, ${ }^{[5]}$ or examining the genetic basis for individual variation in response to therapeutics through pharmacogenomics). ${ }^{[6]}$

\section{THE ASSAY}

The principle of fluorescence-based real-time RT-PCR assays is simple: reverse transcription of RNA is reversetranscribed into cDNA; a suitable detection chemistry reports the presence of PCR products; an instrument monitors the amplification in real time; and an appropriate software analyzes the data. ${ }^{[7]}$ Because the quality of the RNA template is the single most important determinant of the reproducibility of RT-PCR results, ${ }^{[8]}$ it is essential to ensure that no inhibitors copurify during the RNA extraction process. ${ }^{[9]}$

Real-time RT-PCR can be either a one-tube assay using a single buffer, or a two-tube assay where both first-strand cDNA synthesis and the subsequent PCR step are performed separately under optimal conditions for the respective polymerases. The former is more convenient and reduces the risk of cross-contamination; ${ }^{[10,11]}$ the latter may be more sensitive and more reproducible. ${ }^{[12]}$

The priming of the cDNA reaction from the RNA template is best performed using oligo-dT or target-specific primers. Although random primers yield the most cDNA, they initiate transcripts from multiple points along the RNA, including ribosomal RNA (rRNA), thus producing more than one cDNA per original target. Oligo-dT priming results in a faithful cDNA representation of the mRNA pool, but it is not a good choice for poor-quality RNA from formalin-fixed archival material. Target-specific primers synthesize the most specific cDNA and provide the most sensitive method of quantification, ${ }^{[13]}$ but require separate priming reactions for each target.

Viral RTs, used mainly in two-step assays, have a relatively high error rate and a strong tendency to pause, hence producing truncated cDNA. ${ }^{[14]}$ Avian Myoblastosis Virus-RT (AMV-RT) is more robust and processive than Moloney Murine Leukemia Virus-RT (MMLV-RT) ${ }^{[15]}$ and retains significant polymerization activity up to $55^{\circ} \mathrm{C},{ }^{[16]}$ whereas native MMLV-RT has significantly less $\mathrm{RNaseH}$ activity than native AMV-RT ${ }^{[17]}$ but is less thermostable. Several DNA-dependent DNA polymerases exhibit both RNA- and DNA-dependent polymerization activities in the presence of $\mathrm{Mn}^{2+} \cdot{ }^{[18,19]}$ It is also possible to use blends of reverse transcriptases in RT-PCR reactions, which can result in higher reverse transcription efficiencies than the individual component enzymes.

\section{CHEMISTRIES}

Detection chemistries fall into two groups:

1. Nonspecific chemistries usually involve the detection of an intercalating dye (e.g., SYBR green I) (Fig. 1A). ${ }^{[20]}$ The PCR product can be verified by plotting fluorescence as a function of temperature to generate a melting curve of the amplicon. ${ }^{[21]}$ Because the melting temperature $\left(T_{\mathrm{m}}\right)$ of the amplicon depends markedly on its nucleotide composition, it is possible to identify the signal obtained from the correct product. A characteristic melting peak at the amplicon's $T_{\mathrm{m}}$ will distinguish it from amplification artefacts that melt at lower temperatures in broader peaks.

2. Specific chemistries make use of template-specific fluorescent probes for each PCR assay. These probes can be structured (e.g., Scorpions, Molecular Beacons) or linear (e.g., TaqMan, Light-Cycler probes). Probes may contain reporters and quenchers, or make use of the quenching properties of the DNA. All operate on the same principle: A fluorescent signal is only generated if the amplicon-specific probe hybridizes to its complementary target (Fig. 1B). 


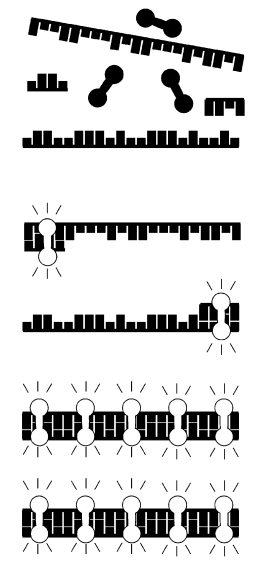

A

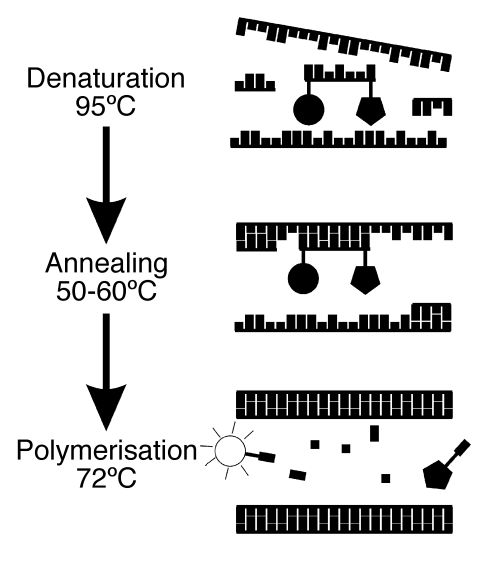

B
Fig. 1 Real-time detection chemistries. (A) Nonspecific (e.g., SYBR green I). In solution, the unbound dye exhibits little fluorescence; during the PCR assay, increasing amounts of dye bind to the nascent double-stranded DNA. When monitored in real time, this results in an increase in the fluorescence signal as the polymerization proceeds, and that falls off during the denaturation step. Consequently, the increasing amounts of amplified DNA can be monitored by measuring the fluorescence measurements at the end of each elongation step. (B) Specific (e.g., 5'-nuclease; TaqMan). Although the fluorophore (circle) and a quencher (pentagon) are bound to the same probe molecule, any light emitted by the fluorophore on excitation is quenched. When the polymerase displaces and cleaves the probe, the fluorophore and the quencher become physically separated, and emissions from the fluorophore can be detected.

\section{INSTRUMENTATION}

Instruments used for real-time PCR use: 1) an excitation light source, to excite the fluorophores; 2) a detector, to register photon emissions that are proportional to the concentration of the amplification product being measured; and 3) a software, which allows analyses of the data.

Fluorescence emission data are collected from each tube and the levels of background fluorescence detected by the fluorimeter are established. Platform-specific algorithms are used to define a fluorescence threshold. Finally, the algorithm searches the data from each sample for a point that exceeds the baseline. The cycle at which this point occurs is defined as $C_{\mathrm{t}}$ (Fig. 2) and is used to calculate the amount of template present at the beginning of the reaction. ${ }^{[22]}$

\section{DATA ANALYSIS}

Results obtained using real-time RT-PCR assays are significantly less variable than conventional RT-PCR protocols, which can be subject to significant error. ${ }^{[23]}$ In principle, quantification by real-time assays is easy: the more copies of mRNA there are at the beginning of the assay, the fewer cycles of amplification are required to reach the $C_{\mathrm{t}}$. In practice, there are some problems in converting a $C_{\mathrm{t}}$ value into a biologically meaningful copy number. ${ }^{[24]}$

\section{Relative Quantification}

Relative quantification expresses the changes in steadystate mRNA levels of a gene relative to the levels of a coamplified internal control mRNA. ${ }^{[25]}$ Target $C_{\mathrm{t}}$ values are compared directly to an internal reference $C_{\mathrm{t}}$ and results are expressed as ratios of the target-specific signal to the internal reference. This produces a corrected relative value for the target-specific mRNA product, which can be compared between samples and allows an estimate of the relative expression of target mRNA in those samples. Amplification efficiencies of a target and a reference must be similar because they directly affect the accuracy of any calculated expression result and must be incorporated into copy number calculations. ${ }^{[26,27]}$ However, because the expression of the internal control itself is often variable, relative quantification can be misleading. [28]

\section{“Absolute” Quantification}

"Absolute" quantification is not really absolute, but is relative to an external standard curve. ${ }^{[2]}$ A standard dilution series with a known concentration of initial target

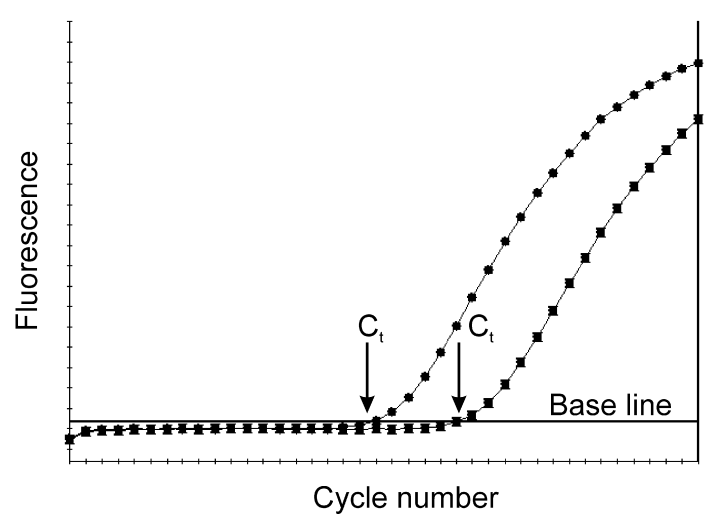

Fig. 2 Threshold cycle $C_{\mathrm{t}}$. The threshold cycle is defined as the number of PCR cycles where the fluorescence generated from the amplification product first exceeds a baseline level. It depends on the sensitivity of the detection system and can vary significantly depending on assay-specific background levels. The two amplification plots have $C_{\mathrm{t}}$ values that differ by six cycles (i.e., represent an approximately 100-fold difference in template starting copy numbers). 
A

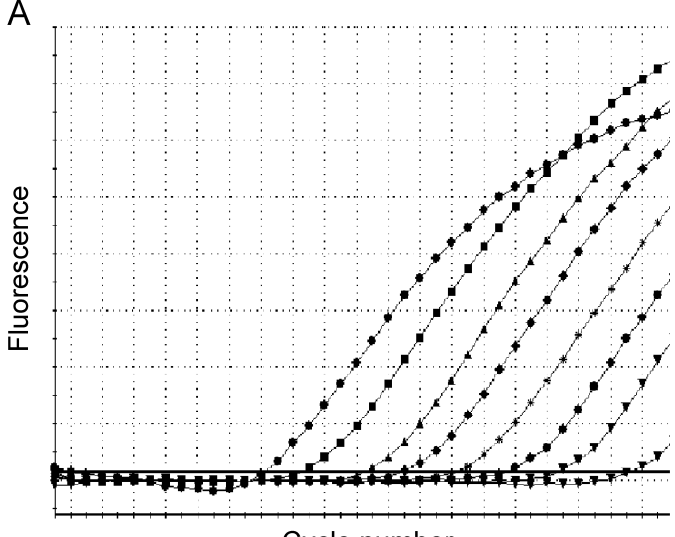

B

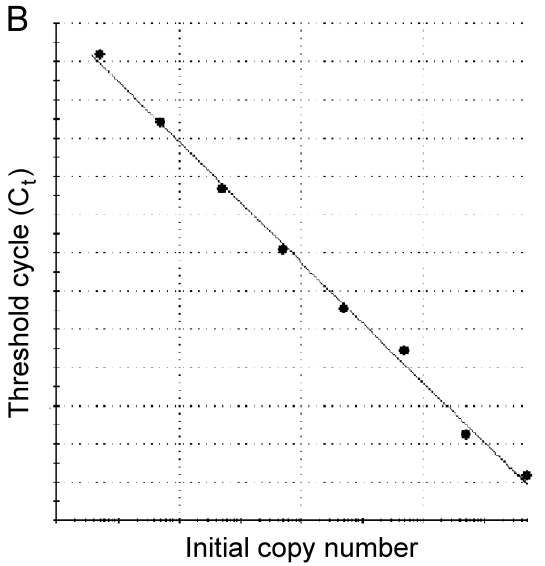

Fig. 3 Preparation of a standard curve. (A) Sense-strand amplicon-specific oligonucleotides are serially diluted from $1 \times 10^{8}$ to 10 copies, and their respective $C_{\mathrm{t}}$ values are recorded. (B) A plot of $C_{\mathrm{t}}$ against the log of the initial oligonucleotide copy number results in a straight line that is linear over at least seven orders of magnitude, and linear regression analysis permits the calculation of the "absolute"' copy number of any unknown target relative to that standard curve.

copy number is used to generate a standard curve by plotting the $C_{\mathrm{t}}$ values against the logarithm of the initial copy numbers (Fig. 3). ${ }^{[29]}$ Its dynamic range must include the $C_{\mathrm{t}}$ values expected for the experimental RNA samples. The copy numbers of unknown samples can be calculated from the linear regression of that standard curve, with the slope providing the amplification efficiency. Standard curves can be constructed from PCR fragments, in vitro T7-transcribed RNA, single-stranded sense-strand oligodeoxyribonucleotides, or commercially available universal reference RNAs. ${ }^{[30]}$

Absolute quantification is most obviously used for quantifying tumor cells or infectious particles such as viruses or bacteria in body fluids, but it is also usefully applied to quantitate changes in mRNA levels. The accuracy of absolute quantification depends entirely on the accuracy of the standards. However, external standards cannot detect or compensate for inhibitors that may be present in the samples.

\section{Data Reporting}

RT-PCR-specific errors in the quantification of mRNA transcripts are easily compounded by any variation in the amount of starting material between samples. ${ }^{[31]}$ This is especially relevant when dealing with in vivo samples that have been obtained from different individuals, or when comparing samples from different tissues.

The most common method for minimizing these errors and correcting for sample-to-sample variation is to amplify a cellular RNA specified by a housekeeping gene that serves as an internal reference against which other RNA values can be normalized. ${ }^{[32]}$ However, because there is no single mRNA with a constant expression level among different tissues of an organism, ${ }^{[33]}$ its use as an internal calibrator is inappropriate. ${ }^{[34]}$ rRNA has been proposed as an alternative normalizer, ${ }^{[35]}$ but there are serious concerns regarding its expression levels, transcription by a different RNA polymerase, and possible imbalances in relative rRNA-to-mRNA content in different cell types that caution against its use as a normalizer. ${ }^{[36]}$ Copy numbers can also be normalized to total cellular RNA and reported as copies per microgram of total RNA. ${ }^{[24]}$ However, total RNA levels may be increased in highly proliferating cells, and this will affect the accuracy of any comparison of copy numbers between normal and tumor cells.

\section{BIOLOGICAL RELEVANCE}

Biopsies contain a range of different cell types-a problem exacerbated in heterogeneous tumor samples that include normal and inflammatory cells as well as diversely evolved cell populations. In addition, normal cells adjacent to a tumor may be phenotypically normal but genotypically abnormal, or exhibit altered gene expression profiles because of their proximity to the tumor. $^{[37]}$ Hence expression profiling of such biopsies provides a composite of the whole population, and this may result in the masking of the expression profile of a specific cell type, or it may be ascribed to and dismissed as illegitimate transcription. ${ }^{[38]}$

Laser capture microdissection (LCM) is useful for accurate expression profiling from such biopsies ${ }^{[39]}$ and has become a powerful technique for extracting pure subpopulations of cells from heterogeneous in vivo cell samples for detailed molecular analysis. ${ }^{[40]}$ Isolation of 
RNA from such small samples is possible, and mRNA expression levels can be accurately and reproducibly quantified ${ }^{[41]}$ even from archival paraffin-embedded tissue specimens ${ }^{[42]}$ and after immunohistochemical staining. ${ }^{[43]}$

\section{APPLICATIONS}

The increasing utility of real-time RT-PCR promises a paradigm shift in molecular clinical diagnostics. Its ability to detect the nucleic acid of a pathogen allows it to identify the actual causes of a disease, as opposed to merely detecting its symptoms. Alterations in mRNA expression profiles are associated with a tissue's reaction to pathological states or drug treatments, and are likely to prove useful for more accurate postoperative staging of cancer patients. Its speed, simplicity, specificity, and sensitivity make this technique ideally suited for this task, making it a cost-effective and time-efficient assay that could become part of a routine protocol of specimen processing.

However, it is important to be aware that issues such as sample processing, assay standardization, and reproducibility, as well as the use of appropriate diagnostic controls, remain to be resolved before real-time RT-PCR can become a realistic practical diagnostic assay. Furthermore, because data interpretation remains highly subjective, there is a need for strict quality control of the reported results to achieve a consistent, standard, and valid diagnosis based on real-time RT-PCR.

\section{CONCLUSION}

Real-time technology has revolutionized the use of, and applications for, RT-PCR assays. However, considerable doubts remain about the reproducibility of real-time RTPCR data, and statistical analyses of the numerical data may obscure the actual results, leaving considerable scope for misinterpretation. Although there can be no doubt of its value as a research tool, its use as a routine clinical diagnostic tool remains unproven.

\section{ACKNOWLEDGMENTS}

I am grateful for the financial support from the Bowel and Cancer Research and the Royal Society.

\section{REFERENCES}

1. Gibson, U.E.; Heid, C.A.; Williams, P.M. A novel method for real time quantitative RT-PCR. Genome Res. 1996, 6 , $995-1001$.
2. Bustin, S.A. Absolute quantification of mRNA using realtime reverse transcription polymerase chain reaction assays. J. Mol. Endocrinol. 2000, 25, 169-193.

3. Halford, W.P.; Falco, V.C.; Gebhardt, B.M.; Carr, D.J. The inherent quantitative capacity of the reverse transcription-polymerase chain reaction. Anal. Biochem. 1999, 266, 181-191.

4. Kappes, J.C.; Saag, M.S.; Shaw, G.M.; Hahn, B.H.; Chopra, P.; Chen, S.; Emini, E.A.; McFarland, R.; Yang, L.C.; Piatak, M., Jr. Assessment of antiretroviral therapy by plasma viral load testing: Standard and ICD HIV-1 p24 antigen and viral RNA (QC-PCR) assays compared. J. Acquir. Immune Defic. Syndr. Human Retrovirol. 1995, 10, 139-149.

5. Bustin, S.A.; Dorudi, S. Molecular assessment of tumour stage and disease recurrence using PCR-based assays. Mol. Med. Today 1998, 4, 389-396.

6. Jung, R.; Soondrum, K.; Neumaier, M. Quantitative PCR. Clin. Chem. Lab. Med. 2000, 38, 833-836.

7. Wittwer, C.T.; Herrmann, M.G.; Moss, A.A.; Rasmussen, R.P. Continuous fluorescence monitoring of rapid cycle DNA amplification. BioTechniques 1997, 22, 130- 138.

8. Bomjen, G.; Raina, A.; Sulaiman, I.M.; Hasnain, S.E.; Dogra, T.D. Effect of storage of blood samples on DNA yield, quality and fingerprinting: A forensic approach. Indian J. Exp. Biol. 1996, 34, 384-386.

9. Cone, R.W.; Hobson, A.C.; Huang, M.L. Coamplified positive control detects inhibition of polymerase chain reactions. J. Clin. Microbiol. 1992, 30, 3185-3189.

10. Aatsinki, J.T.; Lakkakorpi, J.T.; Pietila, E.M.; Rajaniemi, H.J. A coupled one-step reverse transcription PCR procedure for generation of full-length open reading frames. BioTechniques 1994, 16, 282-288.

11. Mallet, F.; Oriol, G.; Mary, C.; Verrier, B.; Mandrand, B. Continuous RT-PCR using AMV-RT and Taq DNA polymerase: Characterization and comparison to uncoupled procedures. BioTechniques 1995, 18, 678687.

12. Vandesompele, J.; De Paepe, A.; Speleman, F. Elimination of primer-dimer artifacts and genomic coamplification using a two-step SYBR green I real-time RT-PCR. Anal. Biochem. 2002, 303, 95-98.

13. Lekanne Deprez, R.H.; Fijnvandraat, A.C.; Ruijter, J.M.; Moorman, A.F. Sensitivity and accuracy of quantitative real-time polymerase chain reaction using SYBR green I depends on cDNA synthesis conditions. Anal. Biochem. 2002, 307, 63-69.

14. Bebenek, K.; Abbotts, J.; Roberts, J.D.; Wilson, S.H.; Kunkel, T.A. Specificity and mechanism of error-prone replication by human immunodeficiency virus-1 reverse transcriptase. J. Biol. Chem. 1989, 264, 16948-16956.

15. Brooks, E.M.; Sheflin, L.G.; Spaulding, S.W. Secondary structure in the 3' UTR of EGF and the choice of reverse transcriptases affect the detection of message diversity by RT-PCR. BioTechniques 1995, 19, 806-815.

16. Freeman, W.M.; Vrana, S.L.; Vrana, K.E. Use of elevated reverse transcription reaction temperatures in RT-PCR. BioTechniques 1996, 20, 782-783.

17. Gerard, G.F.; Fox, D.K.; Nathan, M.; D'Alessio, J.M. 
Reverse transcriptase. The use of cloned Moloney murine leukemia virus reverse transcriptase to synthesize DNA from RNA. Mol. Biotechnol. 1997, 8, 61-77.

18. Myers, T.W.; Gelfand, D.H. Reverse transcription and DNA amplification by a Thermus thermophilus DNA polymerase. Biochemistry 1991, 30, 7661-7666.

19. Harrell, R.A.; Hart, R.P. Rapid preparation of Thermus flavus DNA polymerase. PCR Methods Appl. 1994, 3, 372-375.

20. Morrison, T.B.; Weis, J.J.; Wittwer, C.T. Quantification of low-copy transcripts by continuous SYBR green I monitoring during amplification. BioTechniques 1998, 24, 954-962.

21. Ririe, K.M.; Rasmussen, R.P.; Wittwer, C.T. Product differentiation by analysis of DNA melting curves during the polymerase chain reaction. Anal. Biochem. 1997, 245, $154-160$.

22. Higuchi, R.; Fockler, C.; Dollinger, G.; Watson, R. Kinetic PCR analysis: Real-time monitoring of DNA amplification reactions. Biotechnology (New York) 1993, 11, 10261030.

23. Souaze, F.; Ntodou-Thome, A.; Tran, C.Y.; Rostene, W.; Forgez, P. Quantitative RT-PCR: Limits and accuracy. BioTechniques 1996, 21, 280-285.

24. Bustin, S.A. Quantification of mRNA using real-time reverse transcription PCR (RT-PCR): Trends and problems. J. Mol. Endocrinol. 2002, 29, 23-39.

25. Fink, L.; Seeger, W.; Ermert, L.; Hanze, J.; Stahl, U.; Grimminger, F.; Kummer, W.; Bohle, R.M. Real-time quantitative RT-PCR after laser-assisted cell picking. Nat. Med. 1998, 4, 1329-1333.

26. Pfaffl, M.W. A new mathematical model for relative quantification in real-time RT-PCR. Nucleic Acids Res. 2001, 29, E45.

27. Liu, W.; Saint, D.A. A new quantitative method of real time reverse transcription polymerase chain reaction assay based on simulation of polymerase chain reaction kinetics. Anal. Biochem. 2002, 302, 52-59.

28. Hocquette, J.F.; Brandstetter, A.M. Common practice in molecular biology may introduce statistical bias and misleading biological interpretation. J. Nutr. Biochem. 2002, 13, 370-377.

29. Ke, L.D.; Chen, Z.; Yung, W.K. A reliability test of standard-based quantitative PCR: Exogenous vs. endogenous standards. Mol. Cell. Probes 2000, 14, 127135.

30. Pfaffl, M.W.; Hageleit, M. Validities of mRNA quantification using recombinant RNA and recombinant DNA external calibration curves in real-time RT-PCR. Biotechnol. Lett. 2001, 23, 275-282.

31. Thellin, O.; Zorzi, W.; Lakaye, B.; De Borman, B.; Coumans, B.; Hennen, G.; Grisar, T.; Igout, A.; Heinen, E.
Housekeeping genes as internal standards: Use and limits. J. Biotechnol. 1999, 75, 291-295.

32. Karge, W.H.; Schaefer, E.J.; Ordovas, J.M. Quantification of mRNA by polymerase chain reaction (PCR) using an internal standard and a nonradioactive detection method. Methods Mol. Biol. 1998, 110, 43-61.

33. Haberhausen, G.; Pinsl, J.; Kuhn, C.C.; Markert-Hahn, C. Comparative study of different standardization concepts in quantitative competitive reverse transcription-PCR assays. J. Clin. Microbiol. 1998, 36, 628-633.

34. Tricarico, C.; Pinzani, P.; Bianchi, S.; Paglierani, M.; Distante, V.; Pazzagli, M.; Bustin, S.A.; Orlando, C. Quantitative real-time reverse transcription polymerase chain reaction: Normalization to rRNA or single housekeeping genes is inappropriate for human tissue biopsies. Anal. Biochem. 2002, 309, 293-300.

35. Bhatia, P.; Taylor, W.R.; Greenberg, A.H.; Wright, J.A. Comparison of glyceraldehyde-3-phosphate dehydrogenase and 28S-ribosomal RNA gene expression as RNA loading controls for Northern blot analysis of cell lines of varying malignant potential. Anal. Biochem. 1994, 216, 223-226.

36. Solanas, M.; Moral, R.; Escrich, E. Unsuitability of using ribosomal RNA as loading control for Northern blot analyses related to the imbalance between messenger and ribosomal RNA content in rat mammary tumors. Anal. Biochem. 2001, 288, 99-102.

37. Deng, G.; Lu, Y.; Zlotnikov, G.; Thor, A.D.; Smith, H.S. Loss of heterozygosity in normal tissue adjacent to breast carcinomas. Science 1996, 274, 2057-2059.

38. Chelly, J.; Concordet, J.P.; Kaplan, J.C.; Kahn, A. Illegitimate transcription: Transcription of any gene in any cell type. Proc. Natl. Acad. Sci. U. S. A. 1989, 86, 2617-2621.

39. Sugiyama, Y.; Sugiyama, K.; Hirai, Y.; Akiyama, F.; Hasumi, K. Microdissection is essential for gene expression profiling of clinically resected cancer tissues. Am. J. Clin. Pathol. 2002, 117, 109-116.

40. Walch, A.; Specht, K.; Smida, J.; Aubele, M.; Zitzelsberger, H.; Hofler, H.; Werner, M. Tissue microdissection techniques in quantitative genome and gene expression analyses. Histochem. Cell Biol. 2001, 115, 269-276.

41. Bock, O.; Kreipe, H.; Lehmann, U. One-step extraction of RNA from archival biopsies. Anal. Biochem. 2001, 295, 116-117.

42. Lewis, F.; Maughan, N.J.; Smith, V.; Hillan, K.; Quirke, P. Unlocking the archive-Gene expression in paraffinembedded tissue. J. Pathol. 2001, 195, 66-71.

43. Fink, L.; Kinfe, T.; Stein, M.M.; Ermert, L.; Hanze, J.; Kummer, W.; Seeger, W.; Bohle, R.M. Immunostaining and laser-assisted cell picking for mRNA analysis. Lab. Invest. 2000, 80, 327-333. 